Session 2793

\title{
Alumni Perceptions of the Graduate Needs in Business and Finance
}

\author{
Robert J. Gustafson, Jose M. Castro, Pamela V. Hussen \\ The Ohio State University
}

\section{Introduction}

Outcomes assessment implemented during the 1998-1999 academic year ${ }^{1,2}$, allowed for the identification of areas where a gap may exist between importance and preparation of College of Engineering B.S. graduates as perceived by alumni and graduating seniors. Based on earlier input from constituents, one outcome area included in the Ohio State survey was that of business and finance. Based on surveys from across all programs and including seniors, $2^{\text {nd }}, 6^{\text {th }}$ and $15^{\text {th }}$ year alumni, this area showed the fourth largest gap of the twenty-five outcomes areas surveyed. The Outcomes Assessment Committee in its deliberations did not feel it had adequate understanding of the root cause(s) to help programs make definitive changes. As one approach to better understand this difference, a task group from the committee choose to develop a onepage, topic specific survey of alumni to be used during 1999-2000 academic year only. The goal of the survey being to further define what preparation or abilities were of highest priority in this area and how these might be best accomplished. Structure and results from the survey developed are described in this paper.

\section{Survey Development}

The Task Group reviewed topics covered in current business and finance courses ${ }^{3,4}$ taken by engineers in some programs, a newly proposed business minor from the College of Business, and consulted with persons teaching in this area in both colleges. Although literature on inclusion of specific topics in engineering programs was found ${ }^{5,6}$, no recent comprehensive needs assessment for this topic area were found. Using available information, a three-part survey was developed. The first survey part listed nine topics commonly included in courses taught in this area. Alumni were asked for a rating of importance of the topics. The option for adding additional topics and rating their importance was given. The second survey part dealt with preferred ways to introduce the material into the curriculum. Three approaches were described. Participants were asked to rate least to most preferred. An opportunity to suggest an alternative approach was also given. The final part of the survey was an open-ended question asking for brief descriptions of where the person may have benefited from increased knowledge in this area. A draft survey was reviewed by colleagues from the College of Business and a prototype tested with one Departmental Advisory Committee prior to finalization.

The survey was included as an extra one-page with the 1999-2000 alumni surveys. Surveys were mailed to 2,038 alumni of the $2^{\text {nd }}(1997), 6^{\text {th }}(1993)$, and $15^{\text {th }}(1984)$ year alumni groups. Three hundred and ninety two (392) useable responses to this survey were returned. One hundred and six made written comments in response to the third question. 


\section{Results}

3.1 Topics - The table below shows a statistical summary for the responses to the following question.: "How would you rate the importance of the following specific business/finance topics for undergraduate engineering education?" Using a weighting scale of 1 to 5 (1 Not Important to 5 Extremely Important),. They are rank ordered from highest to lowest importance. A listing of all responses given to the "Other" option are shown below in categories designated by the Task Group.

\begin{tabular}{clcc} 
Rank & \multicolumn{1}{c}{ Topic } & Mean & Std. Dev. \\
1 & Project management & $4.24 / 5$ & 0.70 \\
2 & Other (See list below) & $3.96 / 5$ & 1.20 \\
3 & Cost accounting/cost estimating & $3.68 / 5$ & 1.00 \\
4 & Decision analysis & $3.63 / 5$ & 1.03 \\
5 & Finance & $2.97 / 5$ & 0.96 \\
6 & Organizational behavior/organizational theory & $2.94 / 5$ & 1.03 \\
7 & Marketing & $2.83 / 5$ & 1.11 \\
8 & Entrepreneurship & $2.59 / 5$ & 1.08 \\
9 & Business law & $2.41 / 5$ & 1.04
\end{tabular}

Other Topics List:

Management

Management of people.

People skills

Public speaking, technical writing.

Dealing with the corporate lifestyle.

Quality system management.

Finance

Engineering Economics

General principles, ISE 504

Budget cost/benefit analysis.

Cost as an independent variable

Economic parameters.

$\underline{\text { Business }}$

Business case development/cost justification.

Business processes - supply chain, distribution, etc.

Most of the design engineers I work with need to care more about the business side of things.
Require a business plan for design projects increasing in completion as you get close to graduation.

International studies/business.

Accounting

Business accounting.

Activity-based accounting.

Earned value management

Law

Law pertaining to product liability.

Patent/Intellectual property law.

Patent law.

Regulations, international aspects of business currency transfer.

Contract negotiation.

Misc

Process mapping.

Current civil software.

Personal budget.

Informative systems/DBA.

Core engineering center.

Internet use

Approved electives. 
3.2 Method for Inclusion - In the second survey section, the following question was asked: "Which of the following do you think would be the preferred way to introduce more business/finance in the undergraduate curriculum?" Respondents were asked to rank options 1 to 4 (1 least preferred, 4 most preferred). Other approaches was listed as an option. Responses to other approaches, with similar responses combined, are listed below.

\begin{tabular}{clcc} 
Rank & \multicolumn{1}{c}{ Topic } & Mean & Std. Dev. \\
1 & Other approaches (See list below) & $2.47 / 5$ & 1.28 \\
2 & $\begin{array}{l}\text { Add more business/finance courses(s) in lieu of } \\
\text { some others }\end{array}$ & $2.50 / 4$ & 1.16 \\
3 & $\begin{array}{l}\text { Add more business/finance coverage in current } \\
\text { courses }\end{array}$ & $2.89 / 4$ & 0.93 \\
4 & $\begin{array}{l}\text { Increase the business/finance content of the } \\
\text { capstone/design project }\end{array}$ & $2.89 / 4$ & 0.93 \\
\end{tabular}

Other Approaches List:

Add business/finance courses as technical electives.

Provide a pool of courses (electives)with the requirement to take one or two of these courses. (2)

Make business courses BERs. (Basic Educational Requirements)(4)

Remove humanities/electives and replace with business/finance.

Tie business classes in with engineering courses.

Add a new product cost estimation course.

Add a class for finance survey.

Management classes.

Design a business course for engineers(2).

An accounting class for non-accounting majors.

Add more project management/cost estimating/strategic planning courses

Improve business course currently in program.

Require internships.

Expand co-op/internship jobs.

Mini design projects in multiple classes with cost of technology discussion emphasized.

Relate importance of finance/business to engineering in all courses.

Integrate into labs.

Offer engineering degree with a minor in business management.

Team up with a local company on projects.

Interact with local government/business through a new course to study financial data as it relates to a specific project.

A colloquium series or reading list.

1 or 2 credit independent study.

Cross T.A.s with College of Business.

Business communication.

Supply chain management understanding.

Stock market effects on company.

Auditing analysis methods.

Business and finance as it pertains to engineering.

Stress real world problems and situations not mostly research.

Increase EE to a five-year program. 
3.3 Alumni Experience - Respondents were asked to "Please use the back of this sheet to briefly describe specific situations where you would have benefited from increased business/finance knowledge." One hundred and six of the three hundred and ninety-two respondents $(27 \%)$ made written comments. A sampling of thirty typical comments follows.

1. I was heavily involved in a project to operate our facility ... I was very poorly prepared for many of the activities - such as writing a business plan, setting the financial goals and evaluating maintenance issues vs potential profit. The ideas and skills needed to complete these activities are not terribly difficult .... I also believe that these are ideas that can be implemented in a number of existing courses and projects ...

2. As a consultant, I have to analyze and solve business problems from a wide variety of businesses. ... Most Eng students would be bored in basic business classes, and would resent having to take them. Therefore the way to impart this knowledge is via existing courses or, preferably, as a component of the capstone.

3. Students need a more practical understanding of how the business side of engineering works. Such an understanding would have helped me from day one.

4. It is important for an engineer to be aware of cost differences between alternatives.

5. I do not feel that I was at all prepared to manage personal finances and understand topics such as corporate earnings, how the stock market is influenced, what a stock option is, etc which may be very beneficial to prepare for the "real world" and to better understand corporate decisions.

6. I have been involved in a major product development project where we all had to deal with various aspects of business and finance: developing and meeting cost targets, budgeting for equipment and other capital, calculating labor costs, implementing cost reductions in a manufacturing environment, coordinating with marketing during product development and production startup, producing forecasts and volume estimates for new products.

7. Annual departmental budget preparation, review and approval. Specific project financial preparation review and approval. General business goals and direction. Better understanding of "other" departments' needs and goals.

8. A good start would be to teach engineers how to read a financial statement as well as a basic finance course.

9. The internet has changed your students forever - they are well versed in the stock market, analyst reports and what drives market value. An introspective course on how engineering and product development effect corporate value would be valuable.

10. Awareness of the following issues should accompany an individual with a BS degree: 1) Different buckets of money and the ramifications of each (capital, expense, R\&D) 2) Return on investment dollars 3) Cost estimation techniques and scheduling tools - how to form ROM values for labor and materials, project management tools and techniques (personnel time, utilization \%, vacations, personnel and physical resource conflict resolution, Microsoft Project contains all of these variables and more. It is our standard project management tool and experience with it would map directly to a company and whatever tool it uses 4) Quickly make a decision and go with it. Many things can be analyzed to death but environments are so dynamic the optimal solution is never the same. Future decisions are easier to make when more decisions are known and not "coming next week".

11. Design cost is multifaceted with major impacts sometimes conflicting. The matrix management of most companies requires an extremely focused team that understands the 
importance of time to market within the constraints of marketing definition, cost, and performance. Engineers need to learn how to quickly estimate cost alternatives and narrow their decisions to those that can be made in the time allotted. Short design projects with limited decision points leading up to a full fledge senior design project would make more sense.

12. Organization behavior - would have selected an employer with a culture with a closer match to my personality. Project management - would not use current mode as many on the job errors occurred by learning on the job.

13. A brief coverage of cost estimating would be beneficial to me in my current position. Need to know more of the marketing side of things on my projects..

14. My job requires project mgt ability on a day to day basis. Most important skills would be time management, schedule planning (Gantt Charts), and also purchase planning/justification.

15. The addition of courses to the curriculum is not necessary and will not teach the dynamics of projects they will encounter in practice. The engineering courses should be project intensive. The projects should be set up with a business content. .

16. Advancement within the company is linked to ones ability to successfully lead a project.

17. The most important areas of business I use daily are cost management and analysis and financial statements.

18. As a manufacturing/process engineer - operations management, reducing bottlenecking in process lines. As a testing/reliability engineer - marketing, selling a poor product, which is returned for analysis over and over, will result in a lost customer. As a product engineer operations management, increasing process flow/reducing process time (ie reducing a product's burn in time) results in profitability.

19. Project management, bid preparation, reviewing annual reports, cost accounting, departmental management

20. As for adding more business courses I feel this is the wrong approach. It is already possible to take electives if a student desires. I believe a strong foundation of fundamentals of engineering is what I chose my degree for. If I feel a further interest in business then I can pursue a MBA.

21. Managing projects and costs. Preparing estimates for upcoming work (both time and $\$$ estimates). Understanding $401 \mathrm{~K}$ benefits and the factors affecting the market.

22. If you can't market it or sell it, why design it? Engineers need to understand what finance and marketing are thinking in the development process.

23. statistical classes would have been much more useful than high level calculus classes (ie $153,254,255 / 415)$. Stat 520 was much more useful than 153-255 combined.

24. Business fundamentals are very important, but are also very easy to learn on your own. It took very little time to pick up most of the useful financial concepts on the job. Including cost/benefit/risk analysis within design projects may be useful.

25. I was poorly prepared for project proposal and cost estimating in my current job.

26. In my current entry level position, I have had no need for business knowledge

27. ... I do think that one cross functional course with a team project between business, marketing, finance, engineering and technology would be a fantastic experience that would teach all students valuable lessons no matter what each student pursues. 
28. As an engineer whose responsibility concerns quality, I would benefit from business/finance knowledge for the purpose of better relating quality/environment/safety concerns to those who are most interested in business/finance/profit.

29. Project return on investment calculations, understanding effects of savings and combinations of capital investments/amortization, tax effects etc. "How to make a project pay off".

30. Our best engineers factor financial decisions from project concept through implementation and improvement.

\section{Summary and Discussion}

When considering the results for prioritizing topics, project management, cost accounting/cost estimating and decision analysis clearly rated the highest among the specific topics listed for prioritization. Within the "Other Topics" from the respondents, with the exception of those characterized by the task group as management and people skills, many of the topics could be considered focus areas within the larger topics cited.

No clear concurrence on approach to inclusion of more business/finance focus into the curriculum was apparent in the data collected. Specifics cited by respondents showed a very wide range of approaches.

The task group observed that the written comments seem to be very consistent with the priorities indicated in Part A. Importance of including these topics in the capstone design class was very apparent in the comments received.

Results of the survey have been shared by the Outcomes Assessment Committee of the College with each program. Although no specific college-wide action plan has been developed, each program was asked to consider the report's information and respond in its next annual report regarding their use of the information.

Bibliography

1. Gustafson, R. \& Merrill, J. A College-Level Model for Outcomes-Based Assessment. ASEE Annual Conference and Exposition, June 18-21, St. Louis, MO.

2. Gustafson, R. \& Merrill, J. 2000. Developing an Outcomes Assessment Survey for Seniors, Alumni and Managers/Supervisors. ASEE Annual Conference and Exposition, June 18-21, St. Louis, MO.

3. URL: http://www-iwse.eng.ohio-state.edu/\%7Ecoursep/ise504/SylSu00.html; ISE 504 Engineering Economics.

4. URL: http://www-iwse.eng.ohio-state.edu/ coursep/ise640/Syl640Sp00.html; ISE 640 Project Management. 5. Monaghan, P. Student Engineers Take in the Law. The Chronicle of Higher Education, June18, 1999.

6. McGraw, D. Getting Down to e-business. ASEE Prism, October 2000.

\section{ROBERT J. GUSTAFSON}

Robert J. Gustafson is a Professor of Food, Agricultural and Biological Engineering and Associate Dean for Academic Affairs and Student Services for the College of Engineering of The Ohio State University. Dr. 
Gustafson is a registered professional engineer and is actively engaged in development of first-year engineering programs and teaching improvement. Dr. Gustafson received B.S. and M S. degrees in Agricultural Engineering from the University of Illinois in 1971 and 1972 and a Ph.D. in Agricultural Engineering from Michigan State University in 1974.

\section{JOSE M. CASTRO}

Jose M. Castro is an Associate Professor in the Department of Industrial, Welding and Systems Engineering at The Ohio State University. Prior to joining Ohio State, he worked at the GenCorp Technology center for 12 years and Allied Signal Electronic Materials for two years. Dr. Castro received his PhD degree in Chemical Engineering form the University of Minnesota in 1980. His research is in the area Polymer and Composite Processing. He is engaged in the development of new courses on mathematical modeling of materials processing both at the undergraduate and graduate levels.

\section{PAMELA V. HUSSEN}

Pamela V. Hussen is an academic counselor and staff assistant in the Industrial, Welding and Systems Engineering Department at The Ohio State University. She has held this position for eight years and has been active on various College of Engineering and University committees related to student development and progress. Pam received a B.S. in History from Eastern Michigan University in 1969. 